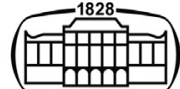

AKADÉMIAI KIADÓ

Acta Veterinaria

Hungarica

68 (2020) 3, 305-309

DOI:

$10.1556 / 004.2020 .00035$

(c) 2020 The Author(s)

RESEARCH ARTICLE

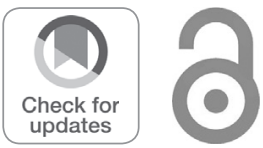

\title{
Serological screening for Coxiella burnetii in the context of early pregnancy loss in dairy cows
}

\author{
ATTILA DOBOS $^{1 *}$, GYÖRGY GÁBOR ${ }^{2}$, ENIKÖ WEHMANN ${ }^{3}$, \\ BÉLA DÉNES ${ }^{4}$, BETTINA PÓTH-SZEBENYI ${ }^{5}$, \\ ÁRON B. KOVÁCS ${ }^{3}$ and MIKLÓS GYURANECZ ${ }^{3}$ \\ ${ }^{1}$ CEVA-Phylaxia Co. Ltd., Szállás u. 5., H-1107, Budapest, Hungary \\ ${ }^{2}$ Androvet Ltd., Budapest, Hungary \\ ${ }^{3}$ Institute for Veterinary Medical Research, Centre for Agricultural Research, Budapest, Hungary \\ ${ }^{4}$ National Food Chain Safety Office, Veterinary Diagnostic Directorate, Budapest, Hungary \\ ${ }^{5}$ National Agricultural Research and Innovation Centre, Research Institute for Animal Breeding, \\ Nutrition and Meat Science, Herceghalom, Hungary
}

Received: June 8, 2020 • Accepted: September 4, 2020

Published online: November 4, 2020

\begin{abstract}
Q fever is one of the commonest infectious diseases worldwide. A Coxiella burnetii prevalence of $97.6 \%$ has been found by ELISA and PCR tests of the bulk tank milk in dairy cattle farms of Hungary. The herd- and individual-level seroprevalence rates of $C$. burnetii in the examined dairy cows and farms have dramatically increased over the past ten years. Three high-producing industrial dairy farms were studied which had previously been found ELISA and PCR positive for C. burnetii by bulk tank milk testing. Coxiella burnetii was detected in 52\% of the 321 cows tested by ELISA. Pregnancy loss was detected in $18 \%$ of the cows between days $29-35$ and days $60-70$ of gestation. The study found a higher seropositivity rate $(80.5 \%)$ in the cows that had lost their pregnancy and a seropositivity of $94.4 \%$ in the first-bred cows that had lost their pregnancy at an early stage. The ELISA-positive pregnant and aborted cows were further investigated by the complement fixation test (CFT). In dairy herds an average of 66.6\% individual seropositivity was detected by the CFT (Phase II) in previously ELISA-positive animals that had lost their pregnancy and $64.5 \%$ in the pregnant animals. A higher (Phase I) seropositivity rate $(50.0 \%)$ was found in the cows with pregnancy loss than in the pregnant animals (38.5\%). The high prevalence of C. burnetii in dairy farms is a major risk factor related to pregnancy loss.
\end{abstract}

\section{KEYWORDS}

Coxiella burnetii, dairy cows, economic loss, pregnancy loss, serology

\section{INTRODUCTION}

Pregnancy loss is one of the most important sources of economic loss in modern industrial dairy farms. Most of the pregnancy losses occur in early pregnancy. Although late embryonic loss and early fetal mortality may occur in a higher percentage of the cows, it is not as easy to detect their infectious or non-infectious causes as those of late fetal loss or abortion. Many specific and nonspecific uterine pathogenic bacteria and several virus infections can change the embryonic environment, causing early pregnancy loss (EPL) (Vanroose et al., 2000). Coxiella burnetii, the causative agent of Q fever, is an obligate intracellular bacterium which is often detected in the uterus (Agerholm, 2013). Many reproductive disorders, such as abortion, retained placenta, metritis and infertility, may be associated with Q fever (Muskens et al., 2011a,b; Muskens et al., 2012; Garcia-Ispierto et al., 2014). Several studies have found that every additional day on which cows are not pregnant at the optimal time after calving and the loss of pregnancy at an early stage cause additional expenses to dairy farms (Meadows et al., 2005). The average value of a new pregnancy was found to be 278 USD in the United States in 2006 (De Vries, 2006). 
Although the percentage incidence of early embryonic loss is higher than that of late embryonic and early fetal loss, the latter causes more serious economic losses to dairy farms because of the delayed rebreeding of cows and the increased culling rates (Diskin and Morris, 2008). The aim of this study was to examine the effect of $C$. burnetii seropositivity by ELISA and complement fixation test (CFT) on early pregnancy and fetal losses in dairy cows between days 29 and 70 of gestation in some Hungarian dairy herds.

\section{MATERIALS AND METHODS}

Data were collected in October and November 2019 from all inseminated cows of three Hungarian dairy farms (herd size: 600,750 and 1,000 cows, milk production: 9,600, 10,200 and $11,000 \mathrm{~kg} /$ cow/year, respectively).

All cows contributing to the data set were Holstein-Friesian, fed a total mixed ration (TMR) and bred by artificial insemination (AI) after a voluntary waiting period of $\sim 60$ days. Pregnancy status was determined by the measurement of serum pregnancy-specific protein B (PSPB) concentrations (29-35 days after AI; $n=321$ ). In all cows initially designated pregnant, continuation of pregnancy or its loss was determined by transrectal palpation 60-70 days after AI. At 29-35 days after insemination, a blood sample from the coccygeal vein of each cow was collected and sent to the laboratory by overnight mail. Upon arrival at the laboratory, blood samples were centrifuged $(670 \times g$ for $10 \mathrm{~min})$ and the resulting sera were assayed for PSPB (BioPRYN ${ }^{\mathrm{TM}}$; Biotracking, Moscow, ID, USA), as described previously (Gábor et al., 2007). On the subsequent day the serum samples were sent to the laboratory for serological testing. All 321 samples were examined by ELISA and all the ELISA-positive animals were further examined by CFT, using C. burnetii phase I and II antigen. Commercial ELISA kits (ID Screen ${ }^{\circledR}$ Q Fever Indirect Multispecies, IDVet Inc., Grabels, France) were used according to the manufacturer's instructions. The serum samples were examined by two different CFT tests, utilising C. burnetii phase I and II antigens, according to the manufacturer's instructions (Virion/Serion GmbH, Würzburg, Germany), and the Manual of Diagnostic Tests and Vaccines for Terrestrial Animals (Word Organisation for Animal Health, 2018).

The percentage pregnancy loss (PPL) was calculated as follows: the calculation used the number of cows diagnosed pregnant at 29-35 days after AI (based on PSPB concentration) and the number of cows diagnosed pregnant by transrectal palpation 60-70 days after AI.

Spearman's rank correlation was applied to analyse the correlation between the positive ELISA test results and the number of pregnancies (ranked as follows: $1=$ positive test result, $0=$ negative test result. The pregnancy loss was represented with rank 1 and continuous pregnancy was ranked 0), using R software (R Core Development Team, 2013).

A dataset was created based of the results of the ELISA testing and the CFT testing, where a pregnancy lost in phase I was marked with 1 and pregnancies lost in phase II were marked with 0 . Similarly, the cows that were pregnant in phase I were marked with 1 and animals that were pregnant in phase II were marked with 0 . The means of the two datasets (pregnant animals in phase I and pregnancy loss in phase I) were compared with Student's $t$-test, using R software (R Core Development Team, 2013).

\section{RESULTS}

The pregnancy rate was $61.9 \%$ (199/321). The rate of pregnancies lost between days 29-35 and days 60-70 of the gestation period was found to be $18 \%$.

ELISA testing showed $52 \%$ individual seropositivity among the cows examined. A higher percentage of C. burnetii positivity was noted in cows that had lost their pregnancy. The seropositivity of cows with pregnancy loss was $80.5 \%$, while that of the pregnant animals was $48.2 \%$ (Fig. 1 ).

Statistical analysis showed a significant positive correlation between positive ELISA test results and the loss of pregnancy (Spearman's rank correlation, rho $=0.282$, $P<0.05)$. ELISA positivity was greatly increased in cows which had lost pregnancy after the first breeding (94.4\%), while in the pregnant animals the seropositivity was only slightly increased (53.8\%) (Fig. 2).

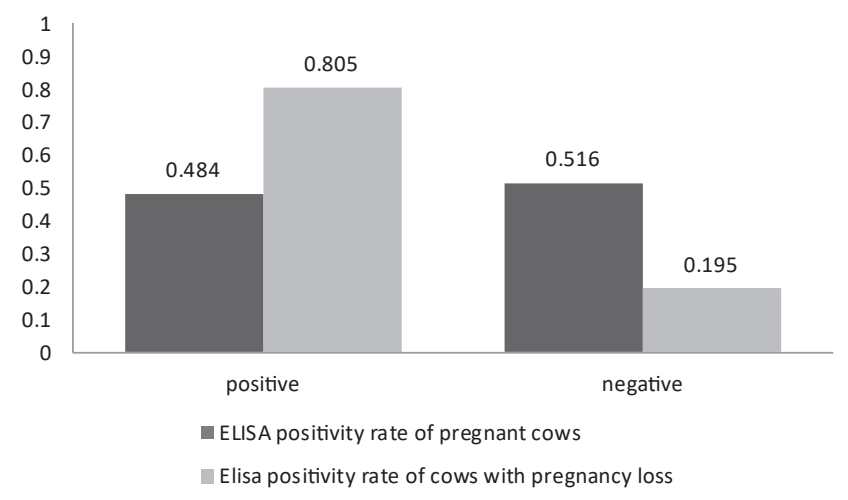

Fig. 1. Coxiella burnetii ELISA positivity and negativity rates of pregnant cows and of cows with pregnancy loss

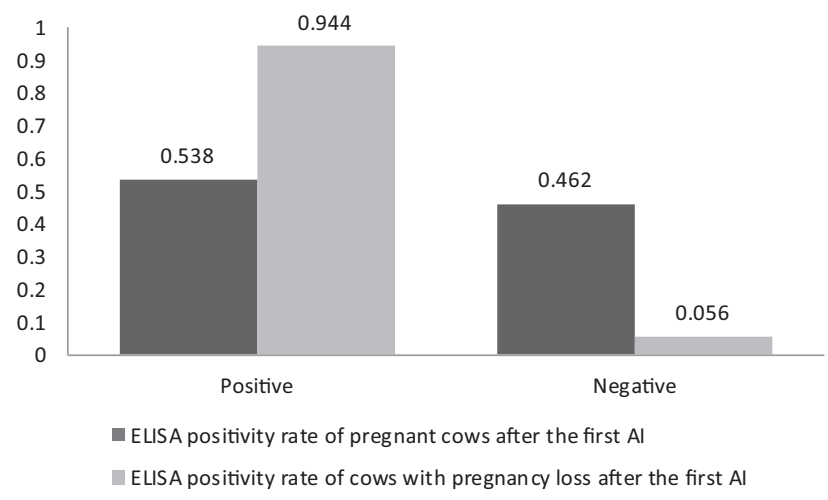

Fig. 2. Coxiella burnetii ELISA positivity and negativity rates in cows pregnant and in cows with pregnancy loss after the first artificial insemination 
Statistical analysis showed a significant positive correlation between positive ELISA test result and the loss of pregnancy at first AI (Spearman's rank correlation, rho = 0.446, $P<0.05)$.

In the dairy herds included in the study, an individual seropositivity rate of $66.6 \%$ was detected in previously ELISApositive animals by CFT (Phase II), $38.8 \%$ of the cows exhibiting low titres $(1: 10-1: 40)$ and $27.7 \%$ high $(<1 / 80)$ titres. CFT (Phase I) detected $49.9 \%$ seropositivity in animals that had lost their pregnancy, with $41.6 \%$ of these cows exhibiting low titres (1:10-1:40) and $8.3 \%$ of them having high $(<1 / 80)$ titres (Table 1). Statistical analysis showed a significant difference in CFT positivity between animals found pregnant in phase I (37/96) and cows that had lost their pregnancy in phase I (18/36) (Student's $t$-test, $P<0.05)$.

\section{DISCUSSION}

The prevalence of C. burnetii infection has been reported to be $93.7 \%$ in Central and Eastern European dairy herds, and a higher prevalence of $97.2 \%$ was found in Hungary based on ELISA and PCR test findings of the bulk tank milk (Dobos et al., 2020). Many laboratory-confirmed human Q fever cases associated with dairy farms have been reported worldwide (Bosnjak et al., 2010). The number of acute human Q-fever infections reported yearly in Hungary ranged between 28 and 59 between 2014 and 2018 (ECDC, 2019). The growing number of cattle in industrial Hungarian dairies and farm structures moving towards concentration increase the risk of $C$. burnetii transmission among animals and from animals to humans.

Several studies have investigated early pregnancy loss in cows between days 28 and 98 after AI. In intensively managed dairy farms of North America the rate of late embryonic loss was found to be $20.2 \%$ (Vasconcelos et al., 1997). Silke et al. (2001) reported 7.2\% late embryonic loss during the same period for dairy cows kept mainly in pasture-based milk production systems in Ireland. LópezGatius (2003) described 10.2\% pregnancy loss from gestation day 38-90 in lactating dairy cows from a single herd in Northern Spain. Zobel et al. (2011) reported a pregnancy loss rate of $7.79 \%$ (in cows and heifers) on two Simmental dairy farms in Croatia from day $32-86$ of gestation. In Hungary, a large number of dairy cattle were tested for pregnancy by assaying serum PSPB concentration at 29-35 days after insemination, and pregnancy was checked again by transrectal palpation 60-70 days after AI. A pregnancy loss of $19.3 \%$ was detected by assaying more than one hundred thousand blood samples (Gábor et al., 2016). The present study found $18.0 \%$ pregnancy loss, which is higher than that reported previously from several other countries. Some authors have stated that embryonic and fetal mortality was not related to the genetic merit of cows (Diskin and Morris, 2008). No significant effect of previous synchronisation on the rate of pregnancy loss was found (LópezGatius et al., 2002). There is evidence that body condition may affect the pregnancy loss rate. Change of body condition was found to increase the incidence of embryonic mortality between days 28 and 56 of gestation (Silke et al., 2001). Negative energy balance during early gestation reduces fertility and may increase the pregnancy loss. LópezGatius et al. (2002) found an about 2.4 times higher risk of pregnancy loss in cows that lost one unit in body condition compared to cows maintaining their body condition. Most authors have found a significant correlation between the incidence of embryonic loss and cow parity (Nyman et al., 2018). Some authors have reported an increase in late embryonic loss with increasing parity (Balendran et al., 2008) and with cow age and endocrine causes (Lee and Kim, 2007; Bajaj and Sharma, 2011). The risk of pregnancy loss was found to be 3.1 times higher in cows with twin pregnancy, as reported by López-Gatius et al. (2012). The uterine environment and periparturient diseases such as subclinical endometritis also have been linked with pregnancy loss (Santos et al., 2004). A recent study has found an association between $C$. burnetii infection and endometritis, which may also be related to progressive reproductive disorders such as infertility (De Biase et al., 2018).

Infectious agents may also be associated with embryonic and fetal loss (Vanroose et al., 2000). Some viruses such as bovine viral diarrhoea virus (BVDV), bovine herpesvirus-1 (BoHV-1) and Bluetongue virus can cause pregnancy loss. BVDV is able to reach the embryo and infect it before the placenta is completely formed at around 30-32 days of pregnancy, resulting in embryonic death (McGowan and Kirkland, 1995; Tsuboi et al., 2011). BoHV-1 may be associated with decreased fertility and abortion in early to late gestation. The virus induces the development of chronic necrotising endometritis 31-47 days after AI (Graham, 2013). Infection of cattle by Bluetongue virus in early stages of pregnancy can result in early fetal death, but this virus infection is closely linked with late abortion and some serious malformations (Sperlova and Zendulkova, 2011). Bacterial, protozoal or fungal infections may cause early fetal death but are more closely associated with abortion. The protozoan pathogen Neospora caninum is a well-studied abortifacient infectious agent in cattle. Several publications

Table 1. Summary of complement fixation test (CFT) results of ELISA-positive pregnant cows and cows with a pregnancy loss

\begin{tabular}{lccc}
\hline & $\begin{array}{c}\text { CFT titres 1:10-1:40 } \\
\text { latent infection }\end{array}$ & $\begin{array}{c}\text { CFT titres }>1: 80 \\
\text { evolving infection }\end{array}$ & $\begin{array}{c}\text { CFT positive/total } \\
\text { ELISA positive }\end{array}$ \\
\hline Cows with pregnancy loss, phase II & $14(38.8 \%)$ & $10(27.7 \%)$ & $24 / 36(66.6 \%)$ \\
Cows with pregnancy loss, phase I & $15(41.6 \%)$ & $3(8.3 \%)$ & $18 / 36(50.0 \%)$ \\
Pregnant animals, phase II & $38(39.5 \%)$ & $22(23 \%)$ & $62 / 96(64.5 \%)$ \\
Pregnant animals, phase I & $28(29.1 \%)$ & $9(9.3 \%)$ & $37 / 96(38.5 \%)$ \\
\hline
\end{tabular}


state that $N$. caninum is the leading infectious cause of bovine abortions but is not associated with early pregnancy loss (Wilson et al., 2016).

The individual seroprevalence rates of C. burnetii in the dairy cows tested in this study (52\%) were above both the international average (20.0\%; Guatteo et al., 2012) and the previous Hungarian findings (38\%; Gyuranecz et al., 2012). The C. burnetii seroprevalence rate was much higher in animals that had lost their pregnancy $(80.5 \%)$ than the rate found in pregnant cows or the average individual value. The seroprevalence rate was close to $100 \%$ in first-inseminated heifers that lost their pregnancy (94.4\%).

An average individual seropositivity rate of $50 \%$ was detected by CFT (Phase I) in animals that had lost their pregnancy. Titres between $1 / 10$ and $1 / 40$ are characteristic of a latent infection. Titres of $1 / 80$ or above indicate an active phase of infection. A CFT titre of 1:40 is diagnostic for acute Q fever (Fournier et al., 1998). According to these CFT results both acute and chronic $\mathrm{Q}$ fever can occur during pregnancy. We detected a significantly higher percentage of phase I titres by CFT in animals that had lost their pregnancy. This means that these animals were in the acute phase of the disease due to acute infection and/or the reactivation of bacteria. In mammals, C. burnetii can be reactivated during pregnancy and thus cause reproductive problems (Fournier et al., 1998). Infection with $C$. burnetii at an early stage of gestation increases the chance of pregnancy loss.

In conclusion, the findings of this study indicate an association between pregnancy loss of dairy cows at the early stage of gestation and C. burnetii infection. The high prevalence of $C$. burnetii in dairy farms is a major risk factor related to pregnancy loss. As pregnancy loss is one of the most significant sources of economic loss in dairy farms, further investigations into the possible causative agents are needed.

Declaration of competing interest: CEVA-Phylaxia Co. Ltd. (CEVA Sante Animale, Libourne, France) is the marketing authorisation holder of the vaccine COXEVAC (containing inactivated C. burnetii, strain Nine Mile), with cattle and goats as target species.

\section{ACKNOWLEDGEMENTS}

MG was supported by the Bolyai János Research Fellowship of the Hungarian Academy of Sciences and the Bolyai+ Fellowship (ÚNKP-19-4-ÁTE-1) of the New National Excellence Program of the Ministry of Innovation and Technology. The funder had no role in study design, data collection and interpretation, or the decision to submit the work for publication. The funder CEVA-Phylaxia Co. Ltd., Budapest, Hungary provided support in the form of salary to author $\mathrm{AD}$, but did not have any additional role in study design, data collection and analysis, decision to publish, or preparation of the manuscript.

\section{REFERENCES}

Agerholm, J. S. (2013): Coxiella burnetii associated reproductive disorders in domestic animals - a critical review. Acta Vet. Scand. 55, 13.

Bajaj, N. K. and Sharma, N. (2011): Endocrine causes of early embryonic death. Curr. Res. Dairy Sci. 3, 1-24.

Balendran, A., Gordon, M., Pretheeban, T., Singh, R., Perera, R. and Rajamahedran, R. (2008): Decreased fertility with increasing parity in lactating dairy cows. Can. J. Anim. Sci. 88, 425-428.

Bosnjak, E., Hvass, A. M. S. W., Villumsen, S. and Nielsen, H. (2010): Emerging evidence for $Q$ fever in humans in Denmark: role of contact with dairy cattle. Clin. Microbiol. Infect. 16, $1285-1288$.

De Biase, D., Costagliola, A., Del Piero, F., Di Palo, R., Coronati, D., Galiero, G., Degli Uberti, B., Lucibelli, M. G., Fabbiano, A., Davoust, B., Raoult, D. and Paciello, O. (2018): Coxiella burnetii in infertile dairy cattle with chronic endometritis. Vet. Pathol. 55, 539-542.

De Vries, A. (2006): Economic value of pregnancy in dairy cattle. J. Dairy Sci. 89, 3876-3885.

Diskin, M. G. and Morris, D. G. (2008): Embryonic and early foetal losses in cattle and other ruminants. Reprod. Domest. Anim. 43 (Suppl. 2), 260-267.

Dobos, A., Kreizinger, Zs., Kovács, Á. B. and Gyuranecz, M. (2020): Prevalence of Coxiella burnetii in Central and Eastern European dairy herds. Comp. Immunol. Microbiol. Infect. Dis. 72, 101489. 13/05, 10.1016/j.cimid.2020.101489.

ECDC (2019): Q fever Annual Epidemiological Report for 2018. Introduction to the Annual Epidemiological Report. European Centre for Disease Prevention and Control, Stockholm.

Fournier, P.-E., Marrie, T. J. and Raoult, D. (1998): Diagnosis of Q fever - Minireview. J. Clin. Microbiol. 36, 1823-1834.

Gábor, G., Kastelic, J. P., Abonyi-Tóth, Z., Gábor, P., Endrődi, T. and Balogh, O. G. (2016): Pregnancy loss in dairy cattle: Relationship of ultrasound, blood pregnancy-specific protein B, progesterone and production variables. Reprod. Domest. Anim. 51, 467-473.

Gábor, G., Tóth, F., Ózsvári, L., Abonyi-Tóth, Zs. and Sasser, R. G. (2007): Early detection of pregnancy and embryonic loss in dairy cattle by ELISA tests. Reprod. Domest. Anim. 42, 633636.

Garcia-Ispierto, I., Tutusaus, J. and López-Gatius, F. (2014): Does Coxiella burnetii affect reproduction in cattle? A clinical update. Reprod. Domest. Anim. 49, 529-535.

Graham, D. A. (2013): Bovine herpes virus-1 (BoHV-1) in cattle - a review with emphasis on reproductive impacts and the emergence of infection in Ireland and the United Kingdom. Ir. Vet. J. 66, 15.

Guatteo, R., Joly, A. and Beaudeau, F. (2012): Shedding and serological patterns of dairy cows following abortions associated with Coxiella burnetii DNA detection. Vet. Microbiol. 155, 430-433.

Gyuranecz, M., Dénes, B., Hornok, S., Kovács, P., Horváth, G., Jurkovich, V., Varga, T., Hajtós, I., Szabó, R., Magyar, T., Vass, N., Hofmann-Lehmann, R., Erdélyi, K., Bhide, M. and Dán, Á. (2012): Prevalence of Coxiella burnetii in Hungary: screening of 
dairy cows, sheep, commercial milk samples, and ticks. Vector Borne Zoonotic Dis. 12, 650-653.

Lee, J. I. and Kim, I. H. (2007): Pregnancy loss in dairy cows: the contributing factors, the effects on reproductive performance and the economic impact. J. Vet. Sci. 8, 283-288.

López-Gatius, F. (2003): Is fertility declining in dairy cattle? A retrospective study in northeastern Spain. Theriogenology 60, 89-99.

López-Gatius, F., Almeria, S. and Garcia-Ispierto, I. (2012): Serological screening for Coxiella burnetii infection and related reproductive performance in high producing dairy cows. Res. Vet. Sci. 93, 67-73.

López-Gatius, F., Santolaria, P., Yániz, J., Rutllant, J. and LópezBéjar, M. (2002): Factors affecting pregnancy loss from gestation day 38 to 90 in lactating dairy cows from a single herd. Theriogenology 57, 1251-1261.

McGowan, M. R. and Kirkland, P. D. (1995): Early reproductive loss due to bovine pestivirus infection. Br. Vet. J. 151, 263-270.

Meadows, C., Rajala-Schultz, P. J. and Frazer, G. S. (2005): A spreadsheet-based model demonstrating the nonuniform economic effects of varying reproductive performance in Ohio dairy herds. J. Dairy Sci. 88, 1244-1254.

Muskens, J., van Engelen, E., van Maanen, C., Bartels, C. and Lam, T. J. G. M. (2011a): Prevalence of Coxiella burnetii infection in Dutch dairy herds based on testing bulk tank milk and individual samples by PCR and ELISA. Vet. Rec. 168, 79.

Muskens, J., van Maanen, C. and Mars, M. H. (2011b): Dairy cows with metritis: Coxiella burnetii test results in uterine, blood and bulk milk samples. Vet. Microbiol. 147, 186-189.

Muskens, J., Wouda, W., von Bannisseht-Wijsmuller, T. and van Maanen, C. (2012): Prevalence of Coxiella burnetii infections in aborted fetuses and stillborn calves. Vet. Rec. 170, 260.

Nyman, S., Gustafsson, H. and Berglund, B. (2018): Extent and pattern of pregnancy losses and progesterone levels during gestation in Swedish Red and Swedish Holstein dairy cows. Acta Vet. Scand. 60, 68.
R Core Development Team (2013): A Language and Environment for Statistical Computing. $\mathrm{R}$ Foundation for Statistical Computing, Vienna, Austria.

Santos, J. E. P., Thatcher, W. W., Chebel, R. C., Cerri, R. L. A. and Galvão, K. N. (2004): The effect of embryonic death rates in cattle on the effiacy of oestrous synchronization programs. Anim. Reprod. Sci. 82-83, 513-535.

Silke, V., Diskin, M. G., Kenny, D. A., Boland, M. P., Dillon, P., Mee, J. F. and Sreenan, J. M. (2001): Extent, pattern and factors associated with late embryonic loss in dairy cows. Anim. Reprod. Sci. 71, 1-12.

Sperlova, A. and Zendulkova, D. (2011): Bluetongue: a review. Vet. Med. 56, 430-450.

Tsuboi, T., Osawa, T., Kimura, K., Kubo, M. and Haritani, M. (2011): Experimental infection of early pregnant cows with bovine viral diarrhea virus: Transmission of virus to the reproductive tract and conceptus. Res. Vet. Sci. 90, 174-178.

Vanroose, G., de Kruif, A. and Van Soom, A. (2000): Embryonic mortality and embryo-pathogen interaction. Anim. Reprod. Sci. 60-61, 131-143.

Vasconcelos, J. L. M., Silcox, R. W., Lacerda, J.A., Pursley, J. R. and Wiltbank, M. C. (1997): Pregnancy rate, pregnancy loss, and response to heat stress after $\mathrm{AI}$ at two different times from ovulation in dairy cows. Biol. Reprod. 56, 140.

Wilson, D. J., Orsel, K., Waddington, J., Rajeev, M., Sweeny, A. R., Joseph, T., Grigg, M. E. and Raverty, S. A. (2016): Neospora caninum is the leading cause of bovine fetal loss in British Columbia, Canada. Vet. Parasitol. 218, 46-51.

World Organisation for Animal Health (OIE) (2018): Manual of Diagnostic Tests and Vaccines for Terrestrial Animals. 8th ed. Part 3, Section 3.vol. 1, Chapter 3.1.16. Q fever (version adopted in May 2018).

Zobel, R., Tkalcic, S., Pipal, I. and Buic, V. (2011): Incidence and factors associated with early pregnancy losses in Simmental dairy cows. Anim. Reprod. Sci. 127, 121-125. 